\title{
REPORT OF THE SUB-COMMITTEE ON FOREIGN RELATIONS, C.S.F.E.
}

$\prod$

THIS Sub-Committee should facilitate contact and co-operation between our foresters and those abroad particularly in matters pertaining to research in forest management.

Personnel.-Chairman, A. Koroleff; Secretary, C. Heimburger

Members.-I. F. Fogh, W. E. D. Halliday, C. D. Howe, T. A. McElhanney and Ellwood Wilson.

Progress.- Some progress has been made in planning the work of this Sub-Committee in the course of preliminary discussions and particularly at the meeting on January 11, 1936. The main subjects of discussions were: extension of contacts, accumulation and centralization of pertient information from abroad, exchange of information between Canadian and foreign foresters, translations etc. First steps for action in these connections have been marked tentatively, such as the need for employment of a technical forester with knowledge of suitable foreign languages to serve the needs mentioned and co-operation with the division of research information of the National Research Council.

Translations.-The relative importance of languages was suggested as follows: by Mr. Halliday (forest geography and silviculture), German, Russian, Swedish, Finnish. By Mr. Harkom (Forest Products), German, Russian, Swedish, Finnish. By Mr. Heimburger (soils), Russian, Swedish, German, French. By Mr. Cook (agriculture), German, French, Spanish. The apparent summary of opinion: German, Russian, French.

Exchange of information. (1) Addresses of suitable foreign foresters and contact through correspondence. (2) Exchange of the publications. (3) Personal contact (trips, exchange of personnel etc.). (4) Exchange of technical papers through society meetings, professional periodicals and governmental channels.

Collection of Foreign Information. (1) Centralizing at one place in Canada scattered data available. (2) Sorting and cataloguing this information. (3) Getting additional information. (4) Tie-up with various organizations cxisting for similar purposes.

Some of the Possible Practical Approaches. Division of research information at the National Research Council can do some translations (according to Mr. Cook). Trained forester with knowledge of the essential languages could be especially employed. Perhaps the Government could be approached 
jointly by the C.S.F.E., the Dominion Forest Service, the Advisory Committee on Forestry and the wood-using industries with a request for funds and perhaps this could be handled through the Advisory Committee on Forestry. The Bureau of Translations, Department of the Secretary of State may be enlisted to co-operate.

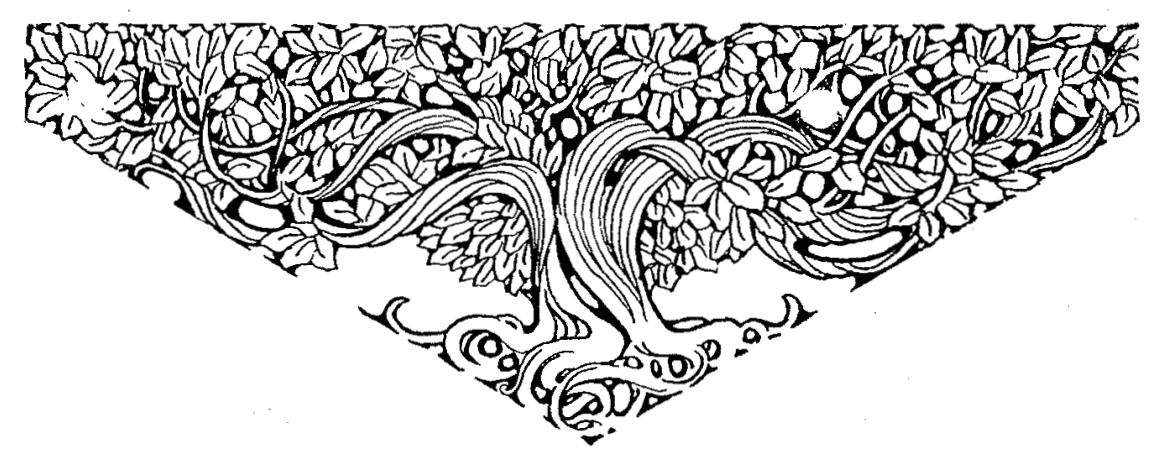

